\title{
Confronting the COVID-19 surgery crisis: time for transformational change
}

\author{
David R. Urbach MD MSc, Danielle Martin MD MPP
}

— Cite as: CMAJ 2020 May 25;192:E585-6. doi: 10.1503/cmaj.200791; early-released May 6, 2020

CMAJ Podcasts: author interview at https://soundcloud.com/cmajpodcasts/200791-com

E lective surgery in Canada has ground to a halt owing to service closures related to the coronavirus disease 2019 (COVID-19) pandemic response. An estimated 45000 fewer surgeries were performed in adults with non-cancer-related illness in Ontario in late March and early April 2020, which is a more than $90 \%$ reduction compared with the same 4-week period in 2019. ${ }^{1}$ Wait times for surgery were unacceptably long even before the pandemic. ${ }^{2}$ Recovering from this surgery backlog will be difficult, and an ethically grounded surgery recovery plan will be required. Such a plan will be logistically difficult in the current delivery model of surgery including resource allocation to surgeons in Canadian hospitals. A team-based, single-entry model approach could help to address the problem in an efficient, fair and ethical manner.

Single-entry models address the wait time problem by creating a single queue that directs each patient to the next available provider based on their acuity and priority in the queue. Teambased care is a further extension of care coordination whereby the surgical care of the patient is shared by a cooperative group of providers; an operation may not be performed by the first surgeon the patient meets, but by another member of the team who is equally skilled and familiar with the particulars of their case.

Single-entry models are informed by queueing theory; are widespread in the airline, banking, restaurant and amusement park industries; ${ }^{3,4}$ and are endorsed by major national medical organizations and commissions. ${ }^{3}$ Whenever single-entry and team-based models of care have been introduced in health care, they have been widely embraced and valued by patients and health care providers; Canadian examples include obstetrics, cardiac surgery, joint replacement, transplantation, cancer surgery, acute care and elective general surgery. ${ }^{3,5,6}$ Furthermore, singleentry models are overwhelmingly preferred by referring physicians. ${ }^{7}$ Advocates of these models emphasize how they reduce and harmonize wait times for specialist care and elective surgery. ${ }^{2}$

Most surgeons in Canada work as solo providers who accept consultation requests from referring physicians and subsequently "own" the care of each patient throughout the entire episode of care. Although some view the personal relationship between a referring physician, surgeon and patient as sacro-

\section{KEY POINTS}

- The coronavirus disease 2019 (COVID-19) pandemic has profoundly reduced the capacity of health systems to provide scheduled services such as elective surgery and other nonemergency procedures.

- The combination of single-entry models and team-based care is an efficient, fair and ethical approach to addressing the pent-up demand for surgery in the presence of constrained resources.

- Even beyond the COVID-19 pandemic, single-entry models and team-based care are effective strategies to reduce wait times, enhance the patient experience of care and improve surgeons' professional work environments.

sanct, the process is haphazard, inefficient and inequitable. It creates unnecessarily variable wait times - a problem that threatens public confidence in Canada's health systems - and centres care around the surgeon rather than the patient. ${ }^{3}$

As nonemergent surgical services resume, returning to "business as usual" will not be acceptable. The capacity to perform scheduled surgery will be severely constrained as hospitals are continuously but variably stressed by recurring waves of COVID19 and grapple with the health care workforce, the supply chain of equipment and medications, and the potential for virus transmission for the foreseeable future. Creative solutions to managing pent-up demand will be required. Single-entry models satisfy key ethical principles for scarce allocation of resources, including utility, fairness, equity and harmony, and can be flexible to address concerns about patient autonomy.

In normal times, team-based care is considered to be superior, providing opportunities for standardization of decision-making, perioperative preparation and built-in second opinions in complex cases. Currently, surgeons are operating on their partners' patients as an emergency response to COVID-19 epidemics in American hospitals. ${ }^{8}$ If these models of care are so efficient and effective, why are they not already widespread in Canada?

The principal reason is reluctance among surgeons and other health care providers to embrace these models of care. Much of this reluctance is driven by uncertainty and fear - emotions that 
are compounded by the stress of our current public health crisis. Many believe that the existing processes for patient referrals work well to ensure that patients are directed to the best and most appropriate care and that the relationship between a surgeon and a patient - once formed - should never be disturbed. Surgeons have legitimate concerns about their professional autonomy, independence, referral base and financial security.

But surgeons' concerns should not impede efforts to introduce innovative strategies to help guide our way out of the COVID-19 crisis. Concerns about these models are legitimate, but easily addressed. For example, surgeons may feel that patients will accept nothing less than choosing their own surgeon. However, it has been reported that most patients prefer a shorter wait time even if it means seeing the next available provider. ${ }^{4}$ In addition, less than half of patients in a group surgery model reported that having the same surgeon was important; threequarters were comfortable meeting their surgeon for the first time on the day of surgery. ${ }^{6}$

Change is painful at the best of times. In his Harveian Oration at the Royal College of Physicians of London in 1906, Sir William Osler observed that "the pain of a new idea is one of the greatest pains to human nature." ${ }^{\prime \prime}$ At this fraught moment, the idea of system change may seem overwhelming.

Single-entry models and team-based care are suitable only for common and standardized procedures, where every surgeon on the team can provide excellent care. To the extent that there is variation in the quality of care among providers, there is no evidence that the patient or referring physician's choice of surgeons is an effective mechanism to weed out poor performers. ${ }^{10,11}$ Bad care must be addressed by clinical leaders rather than the marketplace; group models of care actually make it easier to identify variations in practice and to support colleagues to improve the appropriateness and reliability of care and enhance surgeons' work environment. ${ }^{12}$

Ultimately, surgeons want to perform operations for their patients. Many feel their careers and livelihoods are threatened by the COVID-19 restrictions on hospital activity. Single-entry models and team-based care are the most equitable mechanisms for ensuring that all surgeons - regardless of gender, years in practice, or existing referral network - have an opportunity to provide care and maintain their skills by allocating them equal access to operating room time. These models of care are the most fair and patient-centred approach to addressing the profound challenges we are facing. Surgeons should join health system and hospital leaders and public policy-makers in adopting this approach as a surgery recovery plan in the immediate aftermath of the COVID-19 pandemic and seize this once-in-a-generation opportunity to kindle a broader transformation of surgical services for a sustainable and ethical health system in Canada.

\section{References}

1. Wait Time Information System (WTIS) portal. Toronto: Cancer Care Ontario. Available: https://www.ccohealth.ca/en/submit-data/wait-time-information -system-portal (accessed 2020 Apr. 21).

2. Urbach DR. Improving access to health services in Canada. Healthc Manage Forum 2018;31:256-60.

3. Lopatina E, Damani Z, Bohm E, et al. Single-entry models (SEMs) for scheduled services: towards a roadmap for the implementation of recommended practices. Health Policy 2017;121:963-70.

4. Damani Z, Conner-Spady B, Nash T, et al. What is the influence of single-entry models on access to elective surgical procedures? A systematic review. BMJ Open 2017;7:e012225.

5. Zwiep TM, Greenberg JA, Balaa F, et al. Impact of group practices on patients, physicians and healthcare systems: protocol for a scoping review. BMJ Open 2018;8:e022164.

6. van den Heuvel B, Vair B, Porter G, et al. Patient compliance with a group model of care: the hernia clinic. Can J Surg 2012;55:259-63.

7. Ramchandani M, Mirza S, Sharma A, et al. Pooled cataract waiting lists: views of hospital consultants, general practitioners and patients. J R Soc Med 2002; 95:598-600.

8. Lancaster EM, Sosa JA, Sammann A, et al. Rapid response of an academic surgical department to the COVID-19 pandemic: implications for patients, surgeons, and the community. J Am Coll Surg 2020 Apr. 9. [Epub ahead of print]. pii: S1072-7515(20)30312-4. doi: 10.1016/j.jamcollsurg.2020.04.007.

9. Osler W. The growth of truth: as illustrated in the discovery of the circulation of the blood: being the Harveian Oration delivered at the Royal College of Physicians, London, October 18th, 1906. BMJ 1906;2:1077-84.

10. Mythbusters. Myth: People use health system report cards to make decisions about their healthcare. Ottawa: Canadian Foundation for Healthcare Improvement; 2006. Available: https://www.cfhi-fcass.ca/SearchResultsNews/06-09-01 /688b46df-525d-4ba9-98ab-7c1c9b1130d0.aspx (accessed 2020 Apr. 21).

11. Burns EM, Pettengell C, Athanasiou T, et al. Understanding the strengths and weaknesses of public reporting of surgeon-specific outcome data. Health Aff (Millwood) 2016;35:415-21.

12. Damani Z, Bohm E, Quan H, et al. Improving the quality of care with a singleentry model of referral for total joint replacement: a preimplementation/ postimplementation evaluation. BMJ Open 2019;9:e028373.

Competing interests: Danielle Martin is employed as an administrator at Women's College Hospital, Toronto, Ont. No other competing interests were declared.

This article has been peer reviewed.

Affiliations: Women's College Hospital and Departments of Surgery and Health Policy, Management and Evaluation (Urbach), University of Toronto; Women's College Research Institute (Urbach); Women's College Hospital and Department of Family and Community Medicine (Martin), University of Toronto; Women's College Hospital Institute for Health System Solutions and Virtual Care (Martin), Toronto, Ont.

Contributors: Both authors made substantial contributions to the conception or design of the work; drafted parts of the work and revised it critically for important intellectual content; gave final approval of the version to be published; and agreed to be accountable for all aspects of the work in ensuring that questions related to the accuracy or integrity of any part of the work are appropriately investigated and resolved.

Correspondence to: David Urbach, david.urbach@wchospital.ca 